\title{
Ensino Religioso em contexto democrático: debate nas escolas públicas contemporâneas
}

\author{
Religious Education in a democratic context: \\ debate in contemporary public schools
}

\author{
Aurenéa Maria de Oliveira*
}

\begin{abstract}
Resumo
Este artigo tem como objetivo examinar a presença contemporânea das religiões no espaço público brasileiro, tendo como eixo de debate nesse processo o Ensino Religioso (ER). Neste aspecto, dialoga-se com a dimensão laica dos estabelecimentos educacionais, especificamente públicos, questionando a pertinência ou não da disciplina em tela neles e enfatizam-se, no decorrer do percurso, reflexões que podem ampliar essa discussão, sobretudo no que se refere a olhares, currículo e conteúdos programáticos. Desse modo, parte-se do pressuposto de que o atual currículo de ER preconiza a sociabilidade da disciplina à medida que sugere que ela promova o desenvolvimento de mecanismos de ensino-aprendizagem em que o ser humano volte-se para a memória de sua própria cultura, retornando, consequentemente, sua busca para a compreensão de fundamentos simbólicos e diversificados que se encontram presentes nela. Sobre isso se entende que o Ensino Religioso solicita ação integrada dentro e fora do ambiente escolar, com proposta interdisciplinar envolvida pela relação entre religião, ciência, cultura e sociedade.
\end{abstract}

Palavras-chave: Ensino Religioso. Democracia. Escola Pública. Cultura. Sociedade.

\begin{abstract}
This article aims to examine the contemporary presence of religions in the Brazilian public space, having as its axis of debate in this process the Religious Teaching. In this aspect, it is in dialogue with the secular dimension of educational establishments, specifically public, questioning the relevance or not of the discipline in question in them and emphasizes, along the way, reflections that can broaden this discussion, especially with the curriculum. Thus, it is assumed that the current Religious Teaching curriculum advocates the sociability of the discipline as it suggests that it promotes the development of teaching-learning mechanisms in which the human being turns to the memory of his own culture, returning, consequently, his search for the understanding of symbolic and diversified foundations that are present in this. It is understood that the Religious Teaching requests integrated action inside and outside the school environment, with an interdisciplinary proposal involved by the relationship between religion, science, culture and society.
\end{abstract}

Keywords: Religious teaching. Democracy. Public School. Culture. Society.

Artigo submetido em 2 de outubro de 2019 e aprovado em 2 de abril de 2020.

*Doutora em Sociologia pela UFPE. Professora adjunta II da UFPE. País de origem: Brasil. E-mail: aurenea@yahoo.com.br 


\section{Introdução}

A ciência moderna indubitavelmente legou-nos avanços, pois tivemos um intenso desenvolvimento de métodos de pesquisa, aparecimento de novas tecnologias e um corpo conceitual e filosófico abrangente com melhoria das condições e expectativa de vida; porém, ela também nos trouxe problemas relacionados principalmente à supervalorização do uso da razão e ao superdimensionamento dos conceitos de universalidade, identidade e verdade/objetividade, em detrimento dos de particularidade, diversidade, ideologia/subjetividade, que redundaram, especialmente em termos sóciopolíticos, em processos de colonização, na escravidão dos negros, na perseguição aos judeus na Segunda Guerra Mundial e na distribuição desigual dos resultados do desenvolvimento material. Neste sentido, é que apesar das inúmeras descobertas e de um maior controle sobre a natureza, a modernidade promoveu situações de desrespeito para com o Outro, revelando a dificuldade de se promover relações de alteridade. (OLIVEIRA, 2006).

Dessa forma, esse Outro - negros, índios, povos colonizados, portadores de deficiências físicas, homossexuais, mulheres etc. - não foi visto como tendo identidade singular, pelo contrário, em tal contexto, sua pluralidade teve como modelo a identidade do europeu, não sendo respeitada em sua diferença (CARDOSO, 2003, p. 128). Assim, é que muito da predisposição à intolerância contemporânea, especificamente no campo da religião, por exemplo, às religiões afro-brasileiras, a muçulmanos, budistas etc., está associada a uma apropriação dessa mentalidade moderna européia, que é alicerçada na filosofia iluminista.

Contudo, em que se sustentou/sustenta essa filosofia do ponto de vista epistemológico? Porque esse seu alicerce foi e tem sido severamente criticado? Onde concepções como as de regularidade, causalidade, controle, domínio, falharam/têm falhado? Onde especialmente tais concepções legaram-nos/legamnos dor, desigualdades, estigmas, desrespeito às diferenças? 
A visão de ciência moderna ergueu-se apoiada em duas grandes premissas: a primeira que afirma "[...] o modelo newtoniano, segundo o qual existe uma simetria entre o passado e o futuro" (WALLERSTEIN, 1996, p. 15), o que implica na ideia de que "[...] nós podemos chegar a certezas, e por esse motivo não precisamos distinguir entre o passado e futuro, uma vez que tudo coexiste num eterno presente" (WALLERSTEIN, 1996, p. 15). E a outra, que se estabelece através do "[...] pressuposto de que existe uma distinção fundamental entre a natureza e os seres humanos, entre a matéria e a mente, entre o mundo físico e o mundo social/espiritual" (WALLERSTEIN, 1996, p. 15) passando assim, a ciência, a partir desta diferenciação, "[...] a ser definida como a busca de leis universais da natureza que se mantivessem verdadeiras para além das barreiras de espaço e tempo". (WALLERSTEIN, 1996, p. 15).

De acordo com Boaventura de Sousa Santos (2001, p. 60), esse modelo de ciência penetrou primeiro nas ciências da natureza incidindo depois, a partir do século XIX, sobre as emergentes ciências sociais. Em suas palavras:

O modelo de racionalidade que preside à ciência moderna constituiu-se a partir da revolução científica do século XVI e foi desenvolvido nos séculos seguintes basicamente no domínio das ciências naturais. Ainda que com alguns prenúncios no século XVIII, é só no XIX que este modelo de racionalidade se estende às ciências sociais emergentes. A partir de então pode falar-se de um modelo global (isto é, ocidental) de racionalidade científica que admite variedade interna, mas que se defende ostensivamente de duas formas de conhecimento não científico (e, portanto, potencialmente perturbadoras): o senso comum e as chamadas humanidades ou estudos humanísticos (em que se incluíam, entre outras, os estudos históricos, filológicos, jurídicos, literários, filosóficos e teológicos). (SANTOS, 2001, p. 60-61).

Esse modelo global de racionalidade moderna, segundo o mesmo, é totalitário porque "[...] nega o caráter racional a todas as formas de conhecimento que não se pautaram pelos seus princípios epistemológicos e pelas suas regras metodológicas" (SANTOS, 2001, p. 61). Desse modo, foi essa racionalidade apropriada pelos cientistas que retirou do campo da ciência outras esferas de saberes como as advindas das religiões, denominando-as de dogmáticas, inferiores, conhecimento do senso comum, isto é, saberes não pautados pelos cânones 
científicos. Mas que cânones científicos são esses? Para Santos, esses cânones consubstanciaram-se:

[...] na teoria heliocêntrica do movimento dos planetas de Copérnico, nas leis de Kepler sobre as órbitas dos planetas, nas leis de Galileu sobre a queda dos corpos, na grande síntese da ordem cósmica de Newton e, finalmente, na consciência filosófica que lhe conferem Bacon e Descartes. (SANTOS, 2001, p. 61).

Ainda segundo esse autor, a luta que estes protagonistas da ciência moderna entabularam foi uma luta contra as formas de dogmatismo e de autoridade, levando o conhecimento científico a se separar do senso comum, da religião, da natureza e consequentemente, elevando a ciência ao status, ao poder de detentora absoluta da verdade (SANTOS, 2001, p. 61-62).

No que se refere à religião, a postura da ciência moderna foi a de negá-la como saber na medida em que procurou desconfiar das evidências imediatas que trazia, estas pautadas na concepção de fé como dogma. No caso da natureza, esta ao ser vista como passiva, eterna e reversível é também negada por que:

[...] não tem qualquer outra qualidade ou dignidade que nos impeça de desvendar os seus mistérios, desvendamento que não é contemplativo, mas antes activo, já que visa conhecer a natureza para a dominar e controlar. Como diz Bacon, a ciência fará da pessoa humana "o senhor e o possuidor da natureza" (1993). (SANTOS, 2001, p. 62).

Neste sentido de dominação da natureza, é que o progresso, passa a ser a palavra de ordem, tendo em vista que em tal contexto, ele é infinito haja vista que foi reforçado pelas conquistas materiais da tecnologia da época (WALLERSTEIN, 1996, p. 16). Dessa maneira, a perspectiva de que através da observação e da experimentação se poderia controlar a natureza à medida que se poderia chegar a obter um conhecimento mais profundo e rigoroso sobre ela, não só gerou o domínio pela previsão, mas igualmente, por meio da produção de tecnologia que possibilitou mais controle sobre os fenômenos naturais. Essa produção material era concebida como um sinal de progresso (OLIVEIRA, 2006). 
Em tal conjuntura científica, onde entre outros, o senso comum, o divino, a política e a subjetividade/emotividade/intencionalidade foram expulsos, a racionalidade, sobretudo matemática, ascendia "[...] não só como instrumento privilegiado de análise, como também lógica da investigação, e ainda o modelo de representação da própria estrutura da matéria" (SANTOS, 2001, p. 63). Desse lugar central da matemática, o autor aponta duas consequências:

Em primeiro lugar, conhecer significa quantificar. O rigor científico aferese pelo rigor das medições. As qualidades intrínsecas do objecto são, por assim dizer, desqualificadas e em seu lugar passam a imperar as quantidades em que eventualmente se podem traduzir. $O$ que não é quantificável é cientificamente irrelevante. Em segundo lugar, o método científico assenta-se na redução da complexidade. O mundo é complicado e a mente humana não pode compreender completamente. Conhecer significa dividir e classificar para depois poder determinar relações sistemáticas entre o que se separou. (SANTOS, 2001, p. 63).

Ainda para Boaventura de Sousa Santos (2001) a noção de conhecimento que dessa percepção cresce, apóia-se numa fragmentação primordial entre as condições iniciais - reino para ele da complicação, do acidente onde se faz necessário selecionar as condições relevantes a se observar - e as leis da natureza reino da simplicidade e da regularidade, onde se faz possível medir com rigor. Esta distinção arbitrária decorre de pressupostos epistemológicos e de regras metodológicas assentadas na ideia de que um conhecimento causal que objetiva à formulação de leis, à luz de regularidades, tem como fim último a previsão do comportamento futuro dos fenômenos. (SANTOS, 2001, p. 63).

Neste ponto é que a perspectiva de que o resultado do fenômeno se produzirá independente do lugar e do tempo em que se dão as condições iniciais, ganha corpo posto que, ignorando a intenção, "[...] (a)s leis da ciência moderna são um tipo de causa formal que privilegia o como funciona das coisas em detrimento de qual o agente ou qual fim das coisas". (SANTOS, 2001, p. 64, grifos do autor). Adiante o mesmo afirma que: 
É este tipo de causa formal que permite prever e, portanto, intervir no real e que, em última instância, permite à ciência moderna responder à pergunta sobre os fundamentos do seu rigor e da sua verdade com o elenco dos êxitos na manipulação e transformação do real. (SANTOS, 2001, p. 64).

Essa postura produz um conhecimento baseado na formulação de leis asseguradas na crença de que o passado se repete no futuro, pois há nesse processo uma ordem. O mundo da matéria, sendo encarado como uma máquina é um mundo "[...] cujas operações se podem determinar exactamente por meio de leis físicas e matemáticas, um mundo estático e eterno a flutuar num espaço vazio, um mundo que o racionalismo cartesiano se torna cognoscível por via da sua decomposição nos elementos que o constituem". (SANTOS, 2001, p. 64).

Essa ideia, que se torna universal, de mundo-máquina constitui um dos pilares da noção de progresso, progresso que representa a transformação do real pela via da tecnologia, por meio de uma racionalidade instrumental que conduz o conhecimento científico a um determinismo mecanicista que se deseja utilitário e funcional à medida que se quer reconhecido mais pela capacidade de dominar e transformar do que, pela capacidade de compreender em profundidade o real (SANTOS, 2001). Nesta perspectiva, através de abordagens como a do evolucionismo social, as ciências sociais também adotaram essa lógica.

Contudo, ao se abordar as ciências sociais faz-se importante frisar o que Santos afirma, ou seja, que o modelo da ciência moderna, que se desenvolveu inicialmente nas ciências da natureza, não transladou para as ciências sociais sem ressalvas, haja vista que figuras como Bacon, Vico e Montesquieu1, entre outros, fizeram uma apropriação do modelo cartesiano por meio de dois tipos de receptividade, tipos estes que em princípio se opõem, mas que ao final convergem. O primeiro é representado por aqueles que se esforçaram para aproximar ao

\footnotetext{
${ }^{1}$ Para Santos, Bacon, ao professar a plasticidade da natureza humana, destacando sua perfectibilidade dadas condições sociais, jurídicas e políticas adequadas, possíveis de serem determinadas com rigor; Vico, ao sugerir a existência de leis que determinam a evolução das sociedades, julgando ser possível prever os resultados das ações coletivas; e Montesquieu, ao estabelecer a relação entre leis jurídicas e leis naturais, criam condições para o transladar da metodologia das ciências naturais para as ciências sociais. (SANTOS, 2001, p. 65)
} 
máximo o método das ciências naturais ao das sociais, asseverando o paradigma moderno; enquanto o segundo foi o realizado pelo grupo daqueles que procuraram diferenciar os dois tipos de ciência, ressaltando as especificidades das ciências sociais em seu objeto e, portanto, em seu método de investigação, em relação às ciências naturais. Neste grupo embora a princípio haja uma negação do paradigma moderno, isso não se dá de maneira total, visto que a aceitação da distinção entre natureza e ser humano, objetividade/subjetividade e transcendência reiteram o modelo de ciência moderna, em suas separações clássicas, separações estas que tanto marcaram o Positivismo e o Iluminismo. (SANTOS, 2001, p. 65).

Em tal cenário, não era de se estranhar que perspectivas como as de secularização, secularidade e secularismo ganhassem força, sobretudo no meio acadêmico e educacional, investindo na perspectiva de fim das religiões; no entanto, tal fim não se deu, pelo contrário, posto que o século $\mathrm{XX}$ exibiu o crescimento delas em diferentes partes do mundo e o XXI tem reiterado este avanço em novos moldes, ou seja, as religiões se mantêm vivas inclusive em espaços que se autoafirmaram e se afirmam laicos, isto é, se autodefinem como não privilegiando nenhuma crença, como os públicos, por exemplo.

Contudo, esta relação complicada e enviesada entre religião, laicização e espaço público no Brasil invadiu o campo da educação através da disciplina de Ensino Religioso (ER), à medida que sua implantação e permanência tiveram e têm como uma de suas metas a estratégia de divulgação de valores cristãos em nossa sociedade, isso feito como uma forma de sobrevivência, em lugares de formação humana, da religião (nos primeiros tempos católica e na atualidade, pentecostal e neopentecostal). Assim, é que este artigo visa discutir essa questão emblemática, tendo como eixo de debate a presença religiosa na esfera pública contemporânea, examinando o caso específico da disciplina de Ensino Religioso no cenário educacional. 


\section{Ensino Religioso em escolas públicas na atualidade}

Esse é um momento importante no Brasil para o debate sobre o Ensino Religioso haja vista a autorização pelo Supremo Tribunal Federal em 2017, do Ensino Religioso confessional nas escolas públicas, o que vai de encontro a nossa atual Constituição Federal que preza pela laicização do Estado brasileiro.

Dito isto, faz-se importante frisar que apesar da atual LDB de 1996, em seu artigo 33 garantir a presença facultativa e laica do ER nas escolas públicas para os estudantes, porém, obrigatória para os estabelecimentos educacionais públicos (BRASIL, 1996), não há um consenso sobre este tipo de ensino nesses espaços e esse é um debate intenso que tem suas origens lá atrás, nas lutas travadas entre laicos e defensores do Ensino Religioso, luta esta estabelecida na área de Educação desde os anos 30 do século passado entre os escolanovistas, favoráveis a uma educação pública gratuita e contrários ao ER, e setores da Igreja Católica, favoráveis ao Ensino Religioso e às escolas privadas. Neste sentido, estas duas posições antagônicas tiveram e ainda têm que negociar, junto com outras, a respeito da manutenção ou não dessa disciplina no currículo escolar. (OLIVEIRA; SILVA, 2012).

Neste aspecto, para Berger e Luckmann (2004), por exemplo, as sociedades contemporâneas são marcadas pelo pluralismo religioso e opostamente ao que ocorria nas sociedades arcaicas e tradicionais, nas quais um único sistema de valores e de crença abarcava a tudo e a todos, na atualidade presenciamos a coexistência de sistemas diversos de valores, de religiões e de sentidos que competem entre si (BERGER, LUCKMANN, 2004). Além da multiplicidade de denominações religiosas, o indivíduo pode escolher entre viver sem qualquer religião ou então, agarrar-se a uma das múltiplas e variadas ideologias modernas ou ainda, viver em trânsito religioso ante o leque de opções que encontra.

Assim para estes autores, o pluralismo religioso atual esboça o fim do monopólio religioso, ou seja, desenha o término da situação em que uma única religião dominava se não todas, mas a maior parte das esferas da vida social. Para 
Mariano (2002), esse pluralismo é uma consequência da própria concepção de laicização do Estado, haja vista que a separação entre poder político e religião conduziu ao quadro de disputa entre as religiões, formando, especialmente nas sociedades de modelo liberal, um mercado religioso. (MARIANO, 2002).

Sobre isso Pierucci (2005) destaca que o Ensino Religioso nas escolas públicas, em sua nova configuração legal e proposta curricular, reflete a desmonopolização do campo religioso brasileiro (PIERUCCI, 2005). Já para Dickie (2003), a presença do ER nas escolas públicas representa a tentativa de recuperação para as religiões, de alguma influência no espaço público, por meio da legitimação de sua autoridade acerca da vida cotidiana e cultural, estas vistas como dilaceradas pelo individualismo e pela falta de valores (DICKIE, 2003). Tal tentativa, entretanto se faz sobre outras bases em relação a períodos anteriores tidos como ecumênicos, pois é mais democrática e preocupada em respeitar as individualidades presentes no esforço conjunto de grupos estratégicos (OLIVEIRA; SILVA, 2012).

Neste sentido, a autora ressalta que a LDB de 1996 - alterada em seu artigo 33 pela Lei Federal 9475/97 - estabeleceu uma nova concepção de Ensino Religioso nas escolas públicas, possibilitando o acesso diversificado das várias religiões a essa esfera. Assim, a configuração atual do ER permite que cosmovisões religiosas, até então ausentes do ensino público, tenham também oportunidade de serem visibilizadas nas escolas públicas, o que abre espaço para que outros grupos e atores religiosos minoritários exerçam alguma influência nesse espaço por meio do ER (OLIVEIRA; SILVA, 2012).

Contudo, é sabido que até pouco tempo nas escolas públicas o ER não se revestia legalmente da forma confessional, mas isso mudou, reitera-se, com a autorização deste modelo pelo Supremo Tribunal Federal em 2017. Com isso, abrese espaço para que as religiões dêem, mediante tal disciplina, alguma visibilidade ao elemento/presença religiosa na esfera pública isso feito de modo proselitista e não laico. Neste aspecto, a busca por visibilidade das religiões via ER para Lui (2006) é notória à medida que contra ou a favor, as instituições religiosas estão 
utilizando o Ensino Religioso como vitrine, sendo este palco de disputas na esfera pública entre aquelas religiões que intensificam sua luta para ali permanecerem e outras que lutam para entrarem nesta esfera. Por conseguinte, os grupos religiosos se articulam em conjunto, visando a exercer alguma influência na formação e na educação de crianças e jovens.

Em relação a isso, Dickie (2003) enfatiza que a grande peculiaridade da questão reside na possibilidade de que esse discurso se tem construído de modo a não enfatizar a competitividade entre religiões, posto que ele é perpassado pela ideologia da ação afirmativa pautada pela temática da inclusão. Ainda para a autora, os defensores do ER nas escolas públicas assumem o discurso público que utiliza princípios da visão liberal, democrática e individualista, enfatizando que o acesso ao referido tipo de ensino é um dos direitos dos cidadãos. (DICKIE, 2003).

Desse modo, o Ensino Religioso nas escolas públicas é destacado pelos grupos religiosos como direito individual dos cidadãos e dever do Estado. Acerca disso, Carneiro (2004) sublinha a intenção de se colocar o religioso como dimensão da existência da coletividade nacional, ou seja, como dever básico do Estado na formação dos cidadãos (CARNEIRO, 2004). Nessa perspectiva, o ER se transforma em um dos direitos do cidadão, isto é, em elemento fundamental para garantir-lhe o pleno exercício de seus direitos no espaço nacional. A religião passa a ser, portanto, um direito de todo cidadão e o Estado brasileiro delega aos diversos grupos religiosos reunidos em uma entidade interconfessional, como o CONER (Conselho Nacional de Ensino Religioso), por exemplo, a tarefa de auxiliar as escolas públicas em tudo aquilo que diga respeito a essa disciplina. Importa frisar: o Estado não delega a uma única confissão religiosa em particular, mas a uma entidade que congrega diversos grupos religiosos (MARIANO, 2002). Desse modo, o CONER e outras organizações interconfessionais e ecumênicas se revelam não apenas como espaços de encontro e aproximação entre as religiões, mas também como campo de lutas, de tensões e de desconfianças entre as diversas confissões. Há que se enfatizar neste ponto, a influência da Igreja Católica dentro das entidades de cunho ecumênico. 
Por outro lado, temos os discursos contra a presença desse tipo de ensino nas escolas públicas que, apoiados principalmente na defesa da religião como espaço da esfera privada, e não de res publica, salientam pontos acerca da passionalidade que a presença do ER pode provocar na sala de aula. Nesse sentido, conforme destacam Diniz e Lionço (2010), o ER no Brasil, ao não ter criado ainda condições de se comprometer com a promoção de um ensino plural e diversificado em sala de aula, pode reforçar estigmas que recaem, em especial, sobre religiões minoritárias. (DINIZ; LIONÇO, 2010).

Contudo, longe de querer esgotar o debate, Giumbelli (2008) salienta que mais que um muro que inviabiliza relações, o interessante neste embate é buscar entender como formas de aceitação do religioso ocorreram/ocorrem dentro do espaço público brasileiro, dito laico, ou seja, compreender modos da presença que permitem legitimamente reconhecer o religioso no espaço público, estes modos interagindo, mesmo que não se conformem apenas por ele e/ou a ele, com o princípio da laicidade (GIUMBELLI, 2008). Nesse aspecto, formas híbridas que permitiram/permitem tais diálogos são reveladoras de dinâmicas que, para além dos discursos pró e contra o ER, revelam singularidades, especificidades de processos nos quais e sobre os quais grupos disputam hegemonias de poder nesse campo. Neste aspecto, diante desse quadro complexo de disputas, para não dizer emblemático, algumas reflexões se fazem relevantes:

$1^{\mathrm{a}}$ ) a de que ter uma religião implica em se apoiar em valores e nós ao adentrarmos em qualquer espaço, seja ele público ou privado, não nos despimos totalmente desses valores como tiramos ou trocamos uma roupa. Sendo assim, gostemos ou não, a presença religiosa encontra-se incrustada na esfera privada e também pública das salas de aula e teremos em algum momento, gostemos ou não, que dialogarmos/confrontarmo-nos com ela.

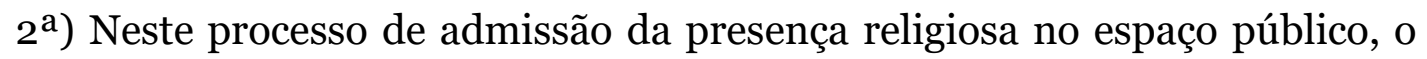
Estado, devendo garantir a pluralização cultural e a democracia, deve para isso, abrir mão de neste espaço, o público, incluindo aí as escolas e as salas 
de aula, defender ou privilegiar, seja diretamente ou sutilmente, qualquer religião, o que vem a reforçar o ideário da laicização.

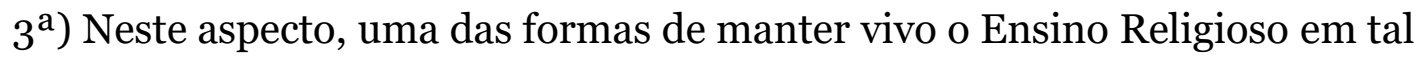
conjuntura relaciona-se com sua ressignificação, inclusive em termos de nomenclatura, pois, existem grupos que defendem, que por conta de seu passado ligado a instituições religiosas cristãs, sobretudo católicas, a disciplina ao invés de Ensino Religioso poderia chamar-se Culturas Religiosas, Antropologia Religiosa ou História das Religiões.

Esta última reflexão acerca da ressignificação da disciplina, com mudança de seu respectivo nome ou não, merece, entretanto, alguns cuidados, estes ligados especificamente aos conteúdos programáticos e ao currículo, isto realizado com o fim de que ela não recaia no tão criticado proselitismo, sobretudo cristão que marcou sua história no Brasil. Quais seriam esses cuidados?

a) em primeiro lugar atentar, como componente curricular, para um novo olhar ao redor das noções de indivíduo e de tolerância, consequentemente de Direitos Humanos, Direitos Humanos estes tão propalados contemporaneamente como um dos eixos de justificação da própria disciplina de Ensino Religioso nas escolas públicas. Neste caso, se não se quiser incorrer na problemática em torno de verdades inquestionáveis, universais e absolutas, advindas das religiões, faz-se pertinente sublinhar uma perspectiva de Ser que dialogue com a ideia de movimento e de construção/desconstrução/reconstrução no qual um constante processo de reformulação religiosa encontra-se atuante junto as e dentro das pessoas. E neste aspecto, tal perspectiva de indivíduo, reverberando sobre a concepção de tolerância, enfatiza o deslizar de uma percepção altruísta, benevolente e cristã de tolerar, para outra que entende este ato como um direito legítimo do outro de ser diferente. Neste sentido, a tolerância não negando o conflito, a competição entre as religiões, todavia, trata o diferente, crente de outra religião ou o ateu, agnóstico ou sem religião, não como inimigo, mas no máximo, como um adversário com quem se disputa algo. Isso reflete uma 
dimensão de Direitos Humanos que atua no sentido de um olhar positivo para a pluralidade e a diversidade posto que, a diferença não é entendida aqui como um estigma, desvio e/ou defeito, e sim como uma presença/pertença que tem seu direito à livre expressão.

b) Um segundo ponto a se tomar cuidado refere-se ao que vai ser estudado na disciplina e ao como se vai estudar. Neste caso, o problema reside em querer tratar a religião como formadora de valores numa dimensão transcendente e não imanente, pois tratando as religiões como sendo de uma esfera não humana, estaremos afirmando que uma, ou umas, estão certas e outras erradas. Entretanto, se nos concentrarmos sobre as cosmologias e/ou cosmovisões das diversas religiões, não importando se minoritárias ou não, e ainda se nos debruçarmos mais nos sentimentos de religiosidade e menos nas filiações a instituições religiosas, saímos de um eixo transcendente de debate, adentrando em outro imanente e histórico delas, isto é, de entendimento das religiões como criações humanas. Fazendo isso se evita cair ou recair na dimensão danosa para a democracia e a pluralidade da Educação Religiosa, tão confundida com o Ensino Religioso, e se entra no âmbito das culturas religiosas, estas tratadas como fenômenos sociais e humanos.

c) Por fim, chama-se a atenção para o se tomar cuidado no trato do perfil com o que diz respeito às pretensões de um Ensino Religioso responsável pela criação de uma cultura de paz. Assim, não se preocupando em gerar grandes expectativas e não se propondo a ser salvacionista, tal ensino poderia caminhar nas escolas como uma disciplina que estimularia o promover a provocar inquietações sociais e culturais acerca de preconceitos e intolerâncias oriundas de visões essencialistas de verdades, difundidas pelas religiões e/ou por certas interpretações feitas delas. A ideia de paz sendo uma construção e não algo dado aprioristicamente, pode ser trabalhada, reitera-se, a partir de elementos de respeito à diferença do outro e não a partir de leituras ecumênicas que muitas vezes, a partir da 
valorização de princípios comuns e na maioria das vezes cristãos, rejeitam essas diferenças e o debate sobre elas, trazendo, principalmente as religiões minoritárias, muito mais para o espaço do controle que para o espaço de um diálogo horizontalizado.

\section{Conclusão}

Para todos os que desejam compreender sobre as cosmologias religiosas, a disciplina de Ensino Religioso, como direito garantido por lei, sendo obrigatória sua oferta pelas instituições escolares públicas (BRASIL, 1996), porém facultativa a matrícula para os alunos, pode se configurar em um espaço de aprendizagem. No currículo desta então, segundo as diretrizes contemporâneas, devem perpassar discussões que envolvam a formação integral dos indivíduos, abordando questões relativas à tolerância, respeito à diversidade e alteridade, visto que hoje as minorias são muito mais visíveis à medida que ao se politizarem, repensaram suas ideias de território e converteram seu estigma em orgulho, reconhecendo suas identidades como uma questão política e cultural.

Sendo assim, o currículo e conteúdos programáticos dessa disciplina podem ser pensados como fazendo parte de todas as ações científicas realizadas no ambiente escolar, sofrendo movimentos constantes de hibridização/reformulação e no contexto atual, faz-se importante a necessidade de uma maior reflexão e diálogo por parte dos profissionais da área quanto à oferta e prática pedagógica que envolve o Ensino Religioso, especificamente nas escolas públicas, visto que apenas os aparatos legais não apresentam a força necessária para seu estabelecimento democrático, no sentido de respeito à diversidade e variedade de pertença religiosa, requerendo assim, uma mudança cultural por parte das próprias instituições escolares para o desenvolvimento de um ER mais equitativo, que atenda a demandas plurais, oportunizando um olhar mais direcionado a questões vinculadas à alteridade. 
Como fora visto, os vários discursos contemporâneos acerca da presença ou não do ER na escola pública expressam ideologias e concepções que envolvem, entre outros fatores, desde o reconhecimento da disciplina como campo de disputa por visibilidade entre as religiões, até sua rejeição na sala de aula. O discurso de manutenção da disciplina via legalidade constitucional ou da LDB repercute em ações escolares, todavia, isso não garante conteúdos que girem ao redor da pluralidade, tolerância e da alteridade com embasamento conceitual reflexivo e laico, ao invés de proselitista e cristão.

Dessa forma, a manutenção dessa disciplina no espaço público educacional pede debates, sobretudo no que se refere a seu currículo, pois este se apresenta como um desafio na realidade atual para este ensino, visto que aceitar sua presença impõe o inibir de práticas proselitistas que durante muito tempo marcaram e ainda marcam seu perfil. Neste aspecto, os discursos acerca do ER evidenciam inadequações e equívocos frente ao que está posto pela legislação, o que reflete posturas estigmatizantes que nos fazem repensar o papel fundamental deste componente curricular na escola enquanto processo de formação do cidadão (OLIVEIRA; MIRANDA; SILVA, 2018).

Neste sentido, um eixo de análise para a construção de propostas curriculares junto a esta disciplina envolvendo questões de diversidade e alteridade, estabelece a questão acerca de como este componente dialoga com perspectivas de cidadania e democracia, haja vista que nesse diálogo pode-se identificar a presença de conteúdos que promovam processos de exclusão social de segmentos religiosos minoritários, como os das religiões afro-brasileiras, por exemplo; por outro lado, pode-se observar se há conteúdo programático investido em processos opostos, isto é, de engajamento social desses grupos, atuando na perspectiva da inclusão deles (OLIVEIRA; SILVA, 2012). Sobre isso, é interessante examinar, nos conteúdos programáticos do ER, possibilidades e limites da participação da sociedade civil nesse processo, isso feito numa perspectiva ao mesmo tempo de confronto e de alteridade junto às diversas cosmologias 
religiosas, levando em consideração nessas construções/desconstruções a presença tanto de antagonismos como de agonismos ${ }^{2}$.

Concomitante a isso, ou seja, a compreensão da construção e elaboração antagônica e/ou agonística do currículo de ER, faz-se pertinente também examinar a reconstrução cultural que dessas propostas são feitas no ensino que ocorre nas salas de aula, isso no sentido de se investigar como o campo da recepção tem levantado discursos acerca da possibilidade de adeptos de instituições religiões participarem dessa organização curricular tanto dentro como fora da escola, o que pode favorecer esses segmentos religiosos, em detrimento dos que dessa organização não participam.

Dessa forma, a análise do diálogo entre religião, cultura e sociedade tem vínculos com o debate acerca da cidadania e da democracia e na proposição discursiva curricular do ER é fundamental perceber o trato dado à questão da inclusão/exclusão social de grupos sociais religiosos com o fim de constatar a promoção/reflexão ou não sobre mecanismos de tolerância/intolerância acionados por segmentos religiosos sobre outros segmentos religiosos. Com isso, os embates discursivos entre os vários setores religiosos no trato da disciplina em tela podem ser lidos de modo a se tentar compreender processos de construções antagônicas ou agnósticas que revelam limites/possibilidades democráticas atuantes na cultura do Ensino religioso.

Sobre isso, estudos observados neste campo contemporaneamente infelizmente ainda dão conta da existência de uma forte cultura de Ensino Religioso marcada pelo proselitismo - o que pode vir a ser reforçado após a decisão do Supremo Tribunal Federal em 2017 - adicionada a práticas híbridas que sinalizam para uma mistura enviesada entre noções de catequese e perspectivas

\footnotetext{
${ }^{2}$ De acordo com Mendonça: "O ponto fundamental da noção filosófica de agonismo - que a diferencia radicalmente da de antagonismo - não é a competição, ou a disputa (que o antagonismo apropriado pela Teoria Política também supõe), mas a existência de regras que fazem com que os adversários partam para sua luta de um ponto comum, de modo que a disputa não ocorra com o fim de destruir o oponente, mas pela legitimidade de um discurso em detrimento de outro. $\mathrm{O}$ 'debate judiciário', a 'competição oratória', diante de um público espectador, representam a competição agônica diante de regras previamente ajustadas e na presença de testemunhas que lhe dão legitimidade" (MENDONÇA, 2003, p. 139), o que não se dá no antagonismo, onde a disputa se estabelece numa relação entre inimigos e não adversários.
} 
tímidas de alteridade e de democracia com respeito à diversidade religiosa. Contudo, sem querer esgotar o debate, acredita-se que muito se tem a caminhar e refletir sobre a importância dessa disciplina na atualidade e neste sentido é que é o dia a dia nas e das salas de aula, com atenção para o que está e o como está sendo visibilizado e invisibilizado no currículo e conteúdo programático dela, pode servir como termômetro para uma avaliação a curto e longo prazo sobre a sua manutenção ou não nas escolas públicas.

\section{REFERÊNCIAS}

BERGER, P.; LUCKMANN, T. Pluralismo, modernidade e crise de sentido. Rio de Janeiro: Vozes, 2004.

BRASIL. Lei no 9.394, de 20 de dezembro de 1996. Estabelece as Diretrizes e Bases da Educação Nacional. Diário Oficial [da] República Federativa do Brasil, Poder Executivo, Brasília, DF, 23 dez. 1996. Disponível em: http://portal.mec.gov.br/arquivos/pdf/ldb.pdf. Acesso em: 09 jul. 2020.

CARDOSO, C. M. Tolerância e seus limites: um olhar latino-americano sobre diversidade e desigualdade. São Paulo: Editora UNESP, 2003.

CARNEIRO, S. M. C. de S. Liberdade religiosa, proselitismo ou ecumenismo: controvérsias acerca da (re) implantação do ensino religioso nas escolas públicas do Rio de Janeiro. Brasil. In: XXVIII ANPOCS, Encontro Anual da ANPOCS, Caxambu, 2004. p. 2-28.

DICKIE, M. A. S. Todos os Caminhos Levam a Deus: O CONER e o ensino religioso em Santa Catarina. Brasil. In: XXVII ANPOCS, Encontro Anual da ANPOCS, Caxambu, 2003. p. 1-26.

DINIZ, D.; LIONÇO, T.; CARRIÃO, V. Laicidade e ensino religioso no Brasil. Brasília: Unesco; Editora UnB, 2010.

GIUMBELLI, E. A Presença do Religioso no Espaço Público: modalidades no Brasil. Religião e Sociedade, Rio de Janeiro, v. 28, n. 2, p. 80-101 ,2008.

LUI, J. de A. Em nome de Deus: um estudo sobre a implementação do ensino religioso nas escolas públicas de São Paulo. 2006. Dissertação (Mestrado em Antropologia Social), Universidade Federal de Santa Catarina, Florianópolis, 2006.

MARIANO, R. Secularização do Estado, Liberdades e Pluralismo Religioso. Equipo Naya, 2002. Disponível em:

http://www.naya.org.ar/congreso2002/ponencias/ricardo_mariano.htm. Acesso em: 07 jul. 2019. 
MENDONÇA, D. de. A NOÇÃO DE ANTAGONISMO NA CIÊNCIA POLÍTICA

CONTEMPORÂNEA: uma análise a partir da perspectiva da Teoria do Discurso. Revista de Sociologia e Política, Curitiba, n. 20, p. 135-145, jun. 2003.

OLIVEIRA, A. M. de. Multiculturalismo, pluralismo e (in) tolerância religiosa: 0 relacionamento dos espíritas pernambucanos com os adeptos de outras religiões (19902004). 2006, 353f. Tese (doutorado em Sociologia), Universidade Federal de Pernambuco, Recife, 2006.

OLIVEIRA, A. M. de; MIRANDA, M. H. G de; SILVA, M. A. M. P. da. Questões de gênero e sexualidade no espaço público educacional tendo como eixo de debate a disciplina de ensino religioso em escolas de Recife. Revista Educação Temática Digital, Campinas: São Paulo, v. 20, n. 4, p. 864-886, out./dez. 2018.

OLIVEIRA, A. M. de; SILVA, D. E. da. Alteridade x intolerância: diretrizes curriculares que podem embasar mais democrática e pluralmente o Ensino Religioso. Revista Teias, Rio de Janeiro, v. 13, n. 27, p. 139-160, jan./abr. 2012.

PIERUCCI, A. F. O desencantamento do mundo: todos os passos do conceito em Max Weber. São Paulo: Editora 34, 2005.

SANTOS, B. V de. A crítica da razão indolente: contra o desperdício da experiência. São Paulo: Cortez, 2001.

WALlerstein, I. Para abrir as Ciências Sociais. São Paulo: Cortez, 1996. 